\title{
Increased Presence of Cognitive Impairment in Hemodialysis Patients in the Absence of Neurological Events
}

\author{
James B. Post ${ }^{a, b, d}$ Kel G. Morin ${ }^{b}$ Mary Sano ${ }^{c, e}$ Adejoke B. Jegede ${ }^{b}$ \\ Erik Langhoffa, d Ann M. Spungen ${ }^{b}$ \\ ${ }^{a}$ Nephrology Division, ${ }^{b}$ VA RR\&D Center of Excellence for Medical Consequences of SCI, James J. Peters Veterans \\ Affairs Medical Center, ' VA RR\&D, James J. Peters Veterans Affairs Medical Center, Bronx, N.Y., and Departments of

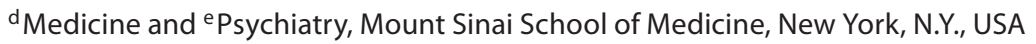

\section{Key Words}

Cognitive impairment $\cdot$ Chronic kidney disease •

Hemodialysis

\begin{abstract}
Background/Aims: Cognitive impairment (Cl) is highly prevalent among hemodialysis (HD) patients and is associated with increased morbidity and mortality. The aim was to compare cognitive function in HD patients with no history of stroke or dementia and well-matched controls. Studies are required to determine the impact of $\mathrm{HD}$ and chronic kidney disease-specific risks on $\mathrm{Cl}$. Methods: 76 outpatients (50 receiving outpatient $\mathrm{HD}$ and 26 with normal kidney function matched for age and comorbidity) underwent a cross-sectional observational study. HD patients were well dialyzed and had optimal hemoglobin levels. A battery of eight neuropsychological tests was used. Outcomes included assessment scores of neurocognitive testing and prevalence and subtype of $\mathrm{Cl}$. Results: Compared to controls, HD subjects had significantly lower composite scores for each tested cognitive domain. In each domain except memory, the percentage of subjects with impairment was significantly higher in HD subjects than controls. Differences between the groups were independent of vascular and dementia risk fac-
\end{abstract}

tors. $82 \%$ of $\mathrm{HD}$ subjects met criteria for $\mathrm{Cl}$ versus $50 \%$ of controls. Non-amnestic subtype of $\mathrm{Cl}$ was more prevalent in both groups. Conclusion: Well-dialyzed HD patients with optimized hemoglobin levels and with no history of stroke or dementia performed significantly worse on multiple measures of cognition compared to controls. A higher prevalence of non-memory impairment may suggest an underlying vascular versus neurodegenerative mechanism. HD and chronic kidney disease-specific risk factors may contribute to early $\mathrm{Cl}$ not readily detected by routine screening methods.

Copyright $\odot 2011$ S. Karger AG, Basel

\section{Introduction}

Studies have shown that the prevalence of cognitive impairment (CI) among hemodialysis (HD) patients is higher than that of the general population $[1,2]$. The consequences of $\mathrm{CI}$ in $\mathrm{HD}$ patients are significant and include increased cost of care, increased mortality, and increased rate of hospitalization [3].

HD patients have multiple traditional cardiovascular risk factors, which are associated with increased risk of $\mathrm{CI}$ and dementia in the general population. However,

\section{KARGER}

Fax +4161306 1234 E-Mail karger@karger.ch www.karger.com
(C) 2011 S. Karger AG, Basel

$0250-8095 / 12 / 0352-0120 \$ 38.00 / 0$

Accessible online at:

www.karger.com/ajn
James B. Post, MD

James J. Peters VA Medical Center

130 West Kingsbridge Road, 4C-12 Outpatient Renal Practice

Bronx, NY 10468 (USA)

Tel. +1 7185849000 , ext. 6635, E-Mail james.post@ @a.goy 
these risk factors may not fully account for the high prevalence of $\mathrm{CI}$ in the HD population. Chronic kidney disease (CKD) severity has been shown to be associated with cognitive decline and dementia independent of traditional vascular risk factors $[4,5]$. Furthermore, HD patients score lower on neurocognitive tests when compared to patients with advanced CKD not yet requiring HD [6]. These findings suggest that CKD and/or factors related to HD may be associated with the higher prevalence of CI. Cyclical hemodynamic stress related to HD coupled with extensive vascular disease may accelerate cognitive deficits characteristic of cerebral microvascular disease.

To better understand the potential role of HD in the development of CI, we proposed to study cognition in well-dialyzed, non-demented HD patients with no clinical history of cerebrovascular disease compared with controls matched for age and comorbidity. We hypothesized that the added vascular risks and hemodynamic stressors imposed by the HD process would result in HD patients having lower scores on neurocognitive testing and a higher percentage of CI compared with matched controls.

\section{Participants and Methods}

\section{Study Participants}

An observational, cross-sectional study of male veterans receiving outpatient HD treatments and general primary care at the James J. Peters VA Medical Center, Bronx, N.Y., was performed. A convenience sample of consecutively encountered individuals was recruited between October 2006 and March 2011. 50 of 100 HD patients were included. For controls, 26 out of approximately 500 non-CKD primary care patients, within the prescribed age range of HD patients, were included. HD participants had to be fluent in English, receiving treatment for at least 3 months and have a 3 -month average urea reduction ratio (URR) of $\geq 65 \%$ at the time of screening. All HD subjects were dialyzed on a 3-dayper-week schedule for 3-4 h each session according to National Kidney Foundation guidelines [7]. Primary care physicians referred patients from their clinics if they met criteria for entry into the study. All subjects provided written, informed consent per regulations of the local institutional review board. Non-CKD control subjects were included if they had normal renal function defined as an eGFR $\geq 60 \mathrm{ml} / \mathrm{min} / 1.73 \mathrm{~m}^{2}$ with or without proteinuria on urinalysis. Control subjects were frequency matched for a history of hypertension (HTN) and/or diabetes mellitus (DM) with the HD subjects. Subjects were excluded if they had chart documentation or knowledge of having a stroke or dementia, a history of Parkinson's disease, other neurodegenerative disease, liver function enzymes (AST and ALT) more than twice the upper limit of normal, or a hemoglobin level $<10 \mathrm{~g} / \mathrm{dl}$. All subjects underwent neuropsychological testing on a non-dialysis day except for 4 patients; 1 was tested just prior to receiving HD therapy and 3 were tested within an hour after HD therapy.
Medical Chart Review, Laboratory and Cognitive Assessments

Demographic characteristics, educational levels, and chronic health conditions were obtained from patients' electronic medical records. All patients, as part of annual clinical care, were screened for depression using the Patient Health Questionnaire-2 (PHQ-2) [8]. For controls, laboratory values for hemoglobin, creatinine, liver function tests, and hemoglobin $A_{1 c}$ were recorded within 6 months of neuropsychological testing. Laboratory values from HD patients included hemoglobin, calcium (Ca), serum phosphorus $\left(\mathrm{PO}_{4}\right)$, parathyroid hormone intact $(\mathrm{PTHi})$ and blood urea nitrogen (BUN) for URR calculation. As part of routine clinical care, these labs are drawn monthly on dialysis days prior to the treatment. Values for $\mathrm{Ca}, \mathrm{PO}_{4}, \mathrm{PTHi}$ and URR were calculated by averaging the monthly labs for 3 consecutive months prior to neuropsychological testing. All tests were performed at a single central laboratory using standard methods. Blood draws were completed within 1 week of neurocognitive testing for homocysteine, and C-reactive protein (CRP). Blood pressure measurements were taken from the day of neuropsychological testing.

A battery of eight validated neuropsychological tests was administered to all study participants. The neuropsychological battery included: the Mini-Mental State Examination (MMSE), the California Verbal Learning Test-II (CVLT-II) Standard Form, the Controlled Oral Word Association Test (COWAT-FAS), animal category fluency, Digit Span, the Symbol Digit Modality Test (SDMT), Trails A \& B, and the Stroop Word \& Color tests. Results of neurocognitive tests were used to classify subjects with CI subtype by using diagnostic criteria utilized from the Cardiovascular Health Cognition Study and the Mayo Clinic Study of Aging as approximate guidelines [9-11]. Subjects with a composite score for long and short delay memory tests $\geq 1.5$ standard deviations (SD) below age-matched norms were classified as CI amnestic type. Study participants who did not meet criteria for CI amnestic type, but scored $\geq 1.5 \mathrm{SD}$ below the norm on two or more tests in a non-memory domain (Attention/Processing Speed, Executive Function, or Language), were classified as CI non-amnestic type.

\section{Statistical Analysis}

For between-group comparisons on each cognitive test, raw scores were converted to age- and education-standardized $\mathrm{T}$ scores. T scores $\geq 1.5 \mathrm{SD}$ below the mean were identified as impaired. To calculate the domain composite $\mathrm{T}$ scores, a mean $\mathrm{T}$ score of all the completed cognitive tests within each particular domain was calculated for each subject. Next, all subjects' individual domain composite scores were averaged within each group to calculate the overall domain composite score for either control or HD groups. Descriptive statistics are reported as mean \pm SD or percent as appropriate. Independent sample t tests were used to evaluate differences between control and HD groups on individual cognitive test T scores and domain composite T scores. Control and HD groups were compared on the demographic and clinical variables represented as a continuous number by using t tests. Multiple regression, two-factor analysis of variance (ANOVA), and logistic regression models were used to adjust for differences between control and HD groups for the following comorbidities: DM, HTN, hyperlipidemia, coronary artery disease, and peripheral vascular disease. A new composite variable for comorbidity was created. Each comorbidity was assigned a single point value. Comorbidity totals for subjects in either group were determined, thus a subject could have $0-5$ points assigned for their comorbid- 
Table 1. Characteristics of study participants

\begin{tabular}{|c|c|c|c|c|}
\hline & $\begin{array}{l}\text { Control }(\mathrm{n}=26) \\
\text { mean } \pm \mathrm{SD}(\min -\max )\end{array}$ & $\begin{array}{l}\mathrm{HD}(\mathrm{n}=50) \\
\text { mean } \pm \mathrm{SD}(\min -\max )\end{array}$ & $\mathrm{p}$ & $\begin{array}{l}\text { Power } \\
(\alpha 0.05)\end{array}$ \\
\hline Age, years & $64 \pm 10(38-84)$ & $63 \pm 10(43-84)$ & 0.9 & 0.06 \\
\hline Education, years & $14 \pm 3(10-22)$ & $13 \pm 2(9-18)$ & 0.08 & 0.4 \\
\hline Body mass index & $29.0 \pm 4.9(19.4-43.4)$ & $28.0 \pm 5.6(19.2-42.2)$ & 0.5 & 0.1 \\
\hline Years on dialysis & $0(\mathrm{~N} / \mathrm{A})$ & $2.5 \pm 3.8(0.3-21)$ & & \\
\hline Urea reduction ratio $(\%)$ & $\mathrm{N} / \mathrm{A}$ & $71 \pm 4(65-82)$ & & \\
\hline Ethnicity, n (\%) & & & 0.3 & \\
\hline African-American & $12(46)$ & $31(62)$ & & \\
\hline Caucasian & $5(19)$ & $10(20)$ & & \\
\hline Other & $9(35)$ & $9(18)$ & & \\
\hline Marital status & & & 0.008 & \\
\hline Married & $13(52)$ & $10(20)$ & & \\
\hline Other & $12(48)$ & $40(80)$ & & \\
\hline \multicolumn{5}{|l|}{ Traditional cardiovascular risk factors } \\
\hline Hypertension & $22(85)$ & $46(92)$ & 0.4 & \\
\hline Diabetes & $18(69)$ & $26(52)$ & 0.2 & \\
\hline Hyperlipidemia & $15(58)$ & $24(48)$ & 0.5 & \\
\hline Systolic blood pressure, $\mathrm{mm} \mathrm{Hg}$ & $134 \pm 19$ & $135 \pm 22$ & 0.9 & 0.04 \\
\hline Diastolic blood pressure, $\mathrm{mm} \mathrm{Hg}$ & $74 \pm 10$ & $72 \pm 13$ & 0.5 & 0.1 \\
\hline Hemoglobin $A_{1 C}, \%^{*}$ & $7.3 \pm 1.7$ & $6.0 \pm 1.1$ & $<0.001$ & 0.9 \\
\hline \multicolumn{5}{|c|}{ Other cardiovascular \& cognitive risk factors } \\
\hline Homocysteine, $\mathrm{mg} / \mathrm{l}^{*}$ & $1.88 \pm 0.55(1.12-2.88)$ & $3.95 \pm 1.30(1.5-7.14)$ & $<0.001$ & 0.9 \\
\hline C-reactive protein, $\mathrm{mg} / \mathrm{l}^{*}$ & $8.7 \pm 12.3(0.6-42.3)$ & $9.4 \pm 13.5(0.6-69.6)$ & 0.8 & 0.04 \\
\hline Hemoglobin, g/dl & $14.1 \pm 1.0(12.5-15.9)$ & $11.5 \pm 1.1(10.0-13.9)$ & $<0.001$ & 0.9 \\
\hline
\end{tabular}

${ }^{*}$ Hemoglobin $\mathrm{A}_{1 \mathrm{C}}$ : control $\mathrm{n}=22, \mathrm{HD} \mathrm{n}=50$; Homocysteine: control $\mathrm{n}=23, \mathrm{HD} \mathrm{n}=49$; C-reactive protein: control $\mathrm{n}=24, \mathrm{HD} \mathrm{n}=42$.

ity status. Hemoglobin, CRP, and homocysteine were also adjusted for in a separate multiple regression model. For the dichotomous or categorical variables, $\chi^{2}$ tests were used to determine the significance of differences in prevalence between the groups. The statistical analyses were performed using StatView (SAS, 1998). Because the sample sizes between the two groups (HD, control) were uneven, a harmonic mean was calculated for the sample size [12]. Statistical power calculations were performed for each outcome variable using the Simple Interactive Statistical Analysis website [www.quantitativeskills.com/sisa/].

\section{Results}

\section{Baseline Characteristics}

Seventy-six male subjects participated in the study, 26 controls and 50 receiving HD. There were no significant differences in demographic variables between the groups (table 1). HTN, DM, hyperlipidemia, peripheral vascular disease, and coronary artery disease were highly prevalent in both groups, with no significant difference between groups. On average, subjects in the HD group dem- onstrated significantly lower hemoglobin and higher homocysteine than those in the control group (table 1).

All subjects scored $\geq 26$ on the MMSE. All subjects screened negative on the PHQ-2. One subject from each group did not complete the Stroop Color \& Stroop ColorWord test secondary to color vision deficiency and these tests were not included for those 2 patients.

\section{T Scores for Individual Tests}

The results for cognitive tests for each domain in HD and control groups are reported (table 2). The HD group scored $\geq 1.5$ SD below the norm on three out of the five measures of attention and processing speed. On measures of executive function, the HD group scored $\geq 1.5$ $\mathrm{SD}$ below the norm on one measure. The HD group performed best on measures of memory (table 2).

By group comparison, HD subjects scored significantly lower than controls on four of five measures of attention and processing speed. The HD group scored significantly lower than controls on all measures of language, executive function, and memory. These group differenc- 
Table 2. Cognitive function T scores by group

\begin{tabular}{|c|c|c|c|c|c|}
\hline Test & Control & HD & $\mathrm{p}$ & Power $\alpha 0.05$ & $\begin{array}{l}\mathrm{p}^{*} \text { (comorbidity } \\
\text { adjustment) }\end{array}$ \\
\hline \multicolumn{6}{|l|}{ Attention and processing speed domain } \\
\hline Trails $\mathrm{A}^{\mathrm{a}}$ & $42 \pm 13$ & $34 \pm 12$ & 0.02 & 0.7 & 0.01 \\
\hline Digit span ${ }^{a}$ & $46 \pm 7$ & $44 \pm 8$ & 0.1 & 0.2 & 0.1 \\
\hline Symbol digit modality test ${ }^{\mathrm{b}}$ & $46 \pm 11$ & $38 \pm 10$ & $<0.001$ & 0.5 & $<0.001$ \\
\hline Stroop Word ${ }^{\mathrm{b}}$ & $36 \pm 10$ & $31 \pm 10$ & 0.04 & 0.5 & 0.03 \\
\hline Stroop Color ${ }^{\mathrm{b}}$ & $38 \pm 9$ & $32 \pm 10$ & 0.02 & 0.7 & 0.01 \\
\hline \multicolumn{6}{|l|}{ Executive function domain } \\
\hline Trails $B^{a}$ & $41 \pm 14$ & $32 \pm 14$ & 0.007 & 0.7 & 0.008 \\
\hline Stroop Color-Word ${ }^{b}$ & $45 \pm 7$ & $39 \pm 8$ & 0.008 & 0.9 & 0.008 \\
\hline \multicolumn{6}{|l|}{ Language domain ${ }^{\mathrm{b}}$} \\
\hline Controlled oral word association test (FAS) & $48 \pm 7$ & $39 \pm 9$ & $<0.001$ & 0.9 & $<0.001$ \\
\hline Animal naming & $49 \pm 10$ & $41 \pm 9$ & $<0.001$ & 0.9 & $<0.001$ \\
\hline \multicolumn{6}{|l|}{ Memory domain ${ }^{\mathrm{a}}$} \\
\hline CVLT total recall & $51 \pm 11$ & $43 \pm 7$ & $<0.001$ & 0.9 & $<0.001$ \\
\hline CVLT short delay recall & $50 \pm 13$ & $43 \pm 10$ & 0.01 & 0.7 & 0.01 \\
\hline CVLT long delay recall & $51 \pm 13$ & $44 \pm 8$ & 0.008 & 0.8 & 0.009 \\
\hline CVLT long delay recognition & $54 \pm 7$ & $42 \pm 13$ & $<0.001$ & 0.9 & $<0.001$ \\
\hline $\begin{array}{l}\text { All tests total control } \mathrm{n}=26, \mathrm{HD} \mathrm{n}=50 \text { exc } \\
{ }^{*} \mathrm{p} \text { values adjusted for diabetes, hypertensio } \\
\text { a Age-adjusted. } \\
{ }^{\mathrm{b}} \text { Age- and education-adjusted (T scores). }\end{array}$ & $\begin{array}{l}\text { he follo } \\
\text { perlipi }\end{array}$ & $\begin{array}{l}\text { roop C } \\
\text { coronar }\end{array}$ & $\begin{array}{l}\text { oop C } \\
\text { disea }\end{array}$ & $\begin{array}{l}\mathrm{d} \text { : control } \mathrm{n}= \\
\text { ripheral vasce }\end{array}$ & $\begin{array}{l}\text { HD n = } 49 \text {. } \\
\text { r disease. }\end{array}$ \\
\hline
\end{tabular}

Table 3. Composite domain $\mathrm{T}$ scores and percent impairment

\begin{tabular}{lccccc}
\hline Domain & Control & HD & $\mathrm{p}$ & Power $\alpha 0.05$ & $\mathrm{p}^{*}$ (comorbidity adjustment) \\
\hline Attention and processing speed & $42 \pm 7$ & $36 \pm 7$ & $<0.001$ & 0.9 & $<0.001$ \\
$\quad$ Impaired (\%) & $6(23)$ & $25(50)$ & 0.03 & & 0.02 \\
Executive function & $42 \pm 10$ & $36 \pm 9$ & 0.004 & 0.7 & $<.005$ \\
$\quad$ Impaired (\%) & $3(12)$ & $24(48)$ & 0.002 & & $<0.001$ \\
Language & $49 \pm 6$ & $40 \pm 7$ & $<0.001$ & 0.9 & $<0.001$ \\
$\quad$ Impaired (\%) & 0 & $15(30)$ & 0.002 & & $<0.001$ \\
Memory & $51 \pm 10$ & $43 \pm 7$ & $<0.001$ & 0.9 & 0.2 \\
$\quad$ Impaired (\%) & $1(4)$ & $6(12)$ & 0.4 & & \\
\hline
\end{tabular}

* $\mathrm{p}$ values adjusted for diabetes, hypertension, hyperlipidemia, coronary artery disease, and peripheral vascular disease.

es remained significant after controlling for comorbidities. Years on dialysis mildly correlated with $\mathrm{T}$ scores for one test of language, the COWAT-FAS $(r=0.35, p=0.01)$.

\section{Composite T Scores and Prevalence of Cognitive}

Impairment by Domain

Composite $\mathrm{T}$ scores for each cognitive domain and the prevalence of impairment for HD and control groups are reported (table 3). The HD group had significantly lower composite $\mathrm{T}$ scores for each domain tested when compared to controls. HD patients demonstrated a significantly higher percentage of impairment in attention and processing speed, executive function, and language versus the control group. These group differences remained significant after controlling for comorbidities. The percentage of patients meeting criteria for memory impairment was not significantly different between the groups and memory was the least impaired domain in HD pa- 


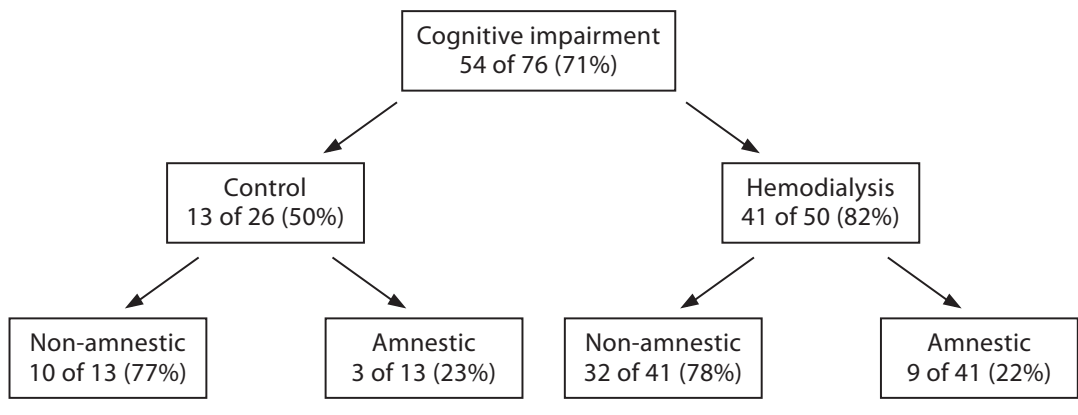

Fig. 1. CI by group and subtype.

tients (12\%). There was no correlation between composite scores and years on dialysis.

\section{Other Vascular and Cognitive Risk Factors}

In the HD group, there were no significant correlations between cognitive performance and any of the following: $\mathrm{PTHi}$ level, $\mathrm{PO}_{4}$, or $\mathrm{Ca} / \mathrm{PO}_{4}$ product. Controlling for hemoglobin, homocysteine, and CRP levels, significant differences between groups remained on all measures and domains.

\section{Prevalence and Subtype of CI}

A flow chart of prevalence and subtype of CI is presented (fig. 1). Criteria for CI were met in $82 \%$ of $\mathrm{HD}$ and $50 \%$ of control subjects. Of HD and control subjects who met criteria for CI, the non-amnestic subtype was more prevalent than the amnestic subtype in each group (78 vs. $22 \% \mathrm{HD}$; 77 vs. $23 \%$ controls) (fig. 1).

\section{Discussion}

Compared to matched controls without CKD, well-dialyzed HD subjects with no history of dementia or stroke scored significantly lower on multiple measures of cognition and had a higher percentage of CI in each tested domain except for memory. Despite all subjects having an MMSE $\geq 26,82 \%$ of HD subjects met criteria for CI versus $50 \%$ for control subjects. These findings suggest that the high prevalence of $\mathrm{CI}$ in $\mathrm{HD}$ patients may not be entirely explained by a heavy burden of cardiovascular risk factors.

A high prevalence of $\mathrm{CI}$ exists among patients receiving HD therapy $[1,2,13]$. Although some studies show a relationship between cognitive function and eGFR inde- pendent of traditional cardiovascular risk factors $[4,5]$, the HD population has mainly been compared to the general population with a lower prevalence of DM, HTN, hyperlipidemia and stroke. The strength of our findings is that we tested well-dialyzed, non-demented HD patients with no clinical history of stroke or cerebrovascular disease, therefore minimizing the influence of uremia, established dementia, and cerebrovascular damage on the results of neurocognitive testing. Furthermore, our control subjects were selected from a similar population to our HD subjects, lessening the differences attributable to cardiovascular risk factors. The findings from this study are consistent with a growing body of evidence that CKD and the HD process may be independent contributors to the high prevalence of $\mathrm{CI}$ in this population.

HD patients have high rates of white matter hyperintensities on magnetic resonance imaging [14, 15], and white matter disease correlates more closely with deficits in executive function and attention/mental processing speed than with deficits within the memory domain [16, 17]. In this study, the CI subtype in both HD patients and controls was predominantly non-amnestic. Additionally, HD subjects scored better on all tests of memory compared to other domains and memory was the only domain where $\mathrm{HD}$ subjects did not have a significantly greater percent impairment versus controls. This pattern of neurocognitive deficits has been observed in similar studies of HD patients and suggests an underlying vascular mechanism $[1,18]$. Even though the HD subjects did not have a clinical history of stroke, neuroimaging was not available to exclude preexisting silent cerebrovascular lesions as a potential etiology for our cognitive findings. Several factors in HD patients are likely to increase the risk of developing white matter lesions. 
Evidence suggests that white matter lesions on magnetic resonance imaging are related to hypoperfusion in the setting of microvascular disease [19]. The hemodynamic alterations associated with HD may play a role in the development of white matter disease. During each dialysis session, volume removal can range from 3 to 4 liters over the course of $4 \mathrm{~h}$. Reductions in middle cerebral artery blood velocity after $\mathrm{HD}$ have been shown to correlate with the volume of fluid removed during the treatment [20]. Progression of cerebral atrophy in HD patients has been associated with hypotensive episodes on HD and number of years receiving $\mathrm{HD}[21,22]$. A progressive decline in white matter and frontal lobe blood flow based on years of $\mathrm{HD}$ are likely to contribute to the pathogenesis of ischemic cerebral damage in HD patients [23]. While HD is lifesaving, the combination of long-term cyclical hemodynamic stress with existing cerebral small vessel disease may be an important contributor to the high prevalence of silent ischemic cerebrovascular disease and characteristic cognitive deficits in these patients.

While subclinical ischemic cerebrovascular disease likely plays a major role in the pathogenesis of $\mathrm{CI}$ in $\mathrm{HD}$ subjects, other CKD-specific risk factors are potential contributors. In this study, PTHi, Ca, $\mathrm{PO}_{4}$, CRP, hemoglobin, and homocysteine levels were not associated with cognitive performance in the HD population.

Although efforts were made to exclude and control for the multiple causes of CI in the HD group, our study has limitations. Our study had a relatively small number of subjects and although stroke was excluded by history and medical record review, neuroimaging was not available. In addition, all of our subjects were male, which limits generalization of our findings to female patients. Anoth- er possible limitation may have been in the diagnosis of CI based on neurocognitive scores in the absence of a subjective clinical complaint of memory or cognitive decline. Due to the cross-sectional design of this study, our observations are at best hypothesis generating.

The prevalence of CI in HD patients is high and is associated with poor outcomes. While the mechanism is likely to be multifactorial, efforts to more clearly define the role of the HD process itself or factors specific to CKD are critical. Increasing HD frequency is associated with improved blood pressure and serum phosphorus control [24] which may attenuate the hemodynamic stress and rate of atherosclerosis in this population. While more frequent HD may not improve cognition, early initiation of such treatments may help lower the incidence of CI by reducing cerebrovascular risk burden. Future studies should evaluate the effect of dialysis modality, frequency, and duration of treatment on cognitive function. Neuroimaging studies in combination with cognitive measures are required to further explain the mechanisms for early $\mathrm{CI}$ in patients receiving $\mathrm{HD}$.

\section{Acknowledgements}

Funding for this project was provided by the VA VISN 3 Seed Grant Program, VA RR\&D CDA 2 \#B5050W, VA RR\&D Center of Excellence \#B4162C and NIH/NIA Alzheimer's Disease Research Center \#AG005138.

\section{Disclosure Statement}

The authors have no conflicts of interest to disclose.

\section{References}

1 Kurella M, Chertow GM, Luan J, Yaffe K: Cognitive impairment in chronic kidney disease. J Am Geriatr Soc 2004;52:18631869.

-2 Murray AM, Tupper DE, Knopman DS, Gilbertson DT, Pederson SL, Li S, Smith GE, Hochhalter AK, Collins AJ, Kane RL: Cognitive impairment in hemodialysis patients is common. Neurology 2006;67:216-223.

3 USRDS 2005 Annual Data Report: Atlas of end-stage renal disease in the United States. Bethesda, National Institutes of Health, $\mathrm{Na}$ tional Institute of Diabetes and Digestive and Kidney Diseases, 2005.
-

Khatri M, Nickolas T, Moon YP, Paik MC, Rundek T, Elkind MS, Sacco RL, Wright CB CKD associates with cognitive decline. J Am Soc Nephrol 2009;20:2427-2432.

5 Kurella Tamura M, Xie D, Yaffe K, Cohen DL, Teal V, Kasner SE, Messe SR, Sehgal AR, Kusek J, Desalvo KB, Cornish-Zirker D, Cohan J, Seliger SL, Chertow GM, Go AS: Vascular risk factors and cognitive impairment in chronic kidney disease: The Chronic Renal Insufficiency Cohort (CRIC) Study. Clin J Am Soc Nephrol 2011;6:248-256.

6 Post JB, Jegede AB, Morin K, Spungen AM, Langhoff E, Sano M: Cognitive profile of chronic kidney disease and hemodialysis patients without dementia. Nephron Clin Pract 2010;116:c247-c255.
7 K/DOQI clinical practice guidelines for chronic kidney disease: evaluation, classification, and stratification. Am J Kidney Dis 2002;39:S1-S266.

$>8$ Kroenke K, Spitzer RL, Williams JB: The Patient Health Questionnaire-2: validity of a two-item depression screener. Med Care 2003;41:1284-1292.

-9 Lopez OL, Kuller LH, Fitzpatrick A, Ives D, Becker JT, Beauchamp N: Evaluation of dementia in the cardiovascular health cognition study. Neuroepidemiology 2003;22:112. 
10 Roberts RO, Geda YE, Knopman DS, Cha RH, Pankratz VS, Boeve BF, Ivnik RJ, Tangalos EG, Petersen RC, Rocca WA: The Mayo Clinic Study of Aging: design and sampling, participation, baseline measures and sample characteristics. Neuroepidemiology 2008; 30:58-69.

11 Petersen RC: Mild cognitive impairment as a diagnostic entity. J Intern Med 2004;256: 183-194.

12 Howell DC: Statistical Methods for Psychology. Belmont, Duxbury Press, 1992.

13 Kurella Tamura M, Larive B, Unruh ML, Stokes JB, Nissenson A, Mehta RL, Chertow GM: Prevalence and correlates of cognitive impairment in hemodialysis patients: the Frequent Hemodialysis Network trials. Clin J Am Soc Nephrol;5:1429-1438.

14 Seliger SL, Sarnak MJ: Subclinical vascular disease of the brain in dialysis patients. Am J Kidney Dis 2007;50:8-10.

-15 Fazekas G, Fazekas F, Schmidt R, Kapeller P, Offenbacher H, Krejs GJ: Brain MRI findings and cognitive impairment in patients undergoing chronic hemodialysis treatment. J Neurol Sci 1995; 134:83-88.
16 Murray ME, Senjem ML, Petersen RC, Hollman JH, Preboske GM, Weigand SD, Knopman DS, Ferman TJ, Dickson DW, Jack CR Jr: Functional impact of white matter hyperintensities in cognitively normal elderly subjects. Arch Neurol 2010;67:1379-1385.

-17 Ylikoski R, Ylikoski A, Erkinjuntti T, Sulkava $R$, Raininko $R$, Tilvis $R$ : White matter changes in healthy elderly persons correlate with attention and speed of mental processing. Arch Neurol 1993;50:818-824.

18 Pereira AA, Weiner DE, Scott T, Chandra P, Bluestein R, Griffith J, Sarnak MJ: Subcortical cognitive impairment in dialysis patients. Hemodial Int 2007;11:309-314.

19 Fernando MS, Simpson JE, Matthews F, Brayne C, Lewis CE, Barber R, Kalaria RN, Forster G, Esteves F, Wharton SB, Shaw PJ, O’Brien JT, Ince PG: White matter lesions in an unselected cohort of the elderly: molecular pathology suggests origin from chronic hypoperfusion injury. Stroke 2006;37:13911398.

20 Stefanidis I, Bach R, Mertens PR, Liakopoulos V, Liapi G, Mann H, Heintz B: Influence of hemodialysis on the mean blood flow velocity in the middle cerebral artery. Clin Nephrol 2005;64:129-137.
21 Kamata T, Hishida A, Takita T, Sawada K, Ikegaya N, Maruyama Y, Miyajima H, Kaneko E: Morphologic abnormalities in the brain of chronically hemodialyzed patients without cerebrovascular disease. Am J Nephrol 2000;20:27-31.

22 Mizumasa T, Hirakata H, Yoshimitsu T, Hirakata E, Kubo M, Kashiwagi M, Tanaka $\mathrm{H}$, Kanai H, Fujimi S, Iida M: Dialysis-related hypotension as a cause of progressive frontal lobe atrophy in chronic hemodialysis patients: a 3-year prospective study. Nephron Clin Pract 2004;97:c23-c30.

23 Kanai H, Hirakata H, Nakane H, Fujii K, Hirakata E, Ibayashi S, Kuwabara Y: Depressed cerebral oxygen metabolism in patients with chronic renal failure: a positron emission tomography study. Am J Kidney Dis 2001; 38:S129-S133.

24 Chertow GM, Levin NW, Beck GJ, Depner TA, Eggers PW, Gassman JJ, Gorodetskaya I, Greene T, James S, Larive B, Lindsay RM, Mehta RL, Miller B, Ornt DB, Rajagopalan S, Rastogi A, Rocco MV, Schiller B, Sergeyeva O, Schulman G, Ting GO, Unruh ML, Star RA, Kliger AS: In-center hemodialysis six times per week versus three times per week. N Engl J Med 2010;363:2287-2300. 